\title{
Satisfaction with Life Scale analyses among healthy people, people with noncommunicable diseases and people with disabilities
}

\author{
ELENA BENDÍKOVÁ ${ }^{1, A-G}$, DAGMAR NEMČEK ${ }^{2, A-G}$, PETRA KURKOVÁ ${ }^{3, \text { B }}$, \\ WIOLETTA LUBKOWSKA ${ }^{4, E}$ F, BOŻENA MROCZEK ${ }^{5, E}$
}

\author{
${ }^{1}$ Department of Physical Education and Sports, Faculty of Humanities, Matej Bel University in Banská Bystrica, \\ Slovakia \\ 2 Department of Sport Educology and Sport Humanities, Faculty of Physical Education and Sports, Comenius \\ University in Bratislava, Slovakia \\ ${ }^{3}$ Department of Anthropology and Health Education, Faculty of Education, Palacký University Olomouc, Czech \\ Republic \\ ${ }^{4}$ Faculty of Physical Education and Health Promotion, University of Szczecin, Poland \\ ${ }^{5}$ Department of Human Sciences in Medicine, Pomeranian Medical University in Szczecin, Poland
}

A - Study Design, B - Data Collection, C - Statistical Analysis, D - Data Interpretation, E - Manuscript Preparation, F - Literature Search, G - Funds Collection

Summary Background. A satisfactory professional and social life of disabled and people with noncommunicable diseases depends on their life satisfaction (LS), which should be understood as a subjective assessment of their past and current life situation, as well as prospects for the future.

Objectives. The aim of this study was to analyze the LS status using SWLS among healthy people, people with noncommunicable diseases and people with disabilities and compare SWLS scores within three evaluated groups.

Material and methods. The study was conducted in 2015 and 2016 in Slovakia. It involved three population groups $(n=1144)$, which were recruited for the study: healthy people (HP; $n=313$ ) people with noncommunicable diseases (PwNCDs; $n=351$ ) and people with disabilities (PwDs; $n=480$ ). The Satisfaction with Life Scale (SWLS) study was used.

Results. The overall SWLS score of the evaluated groups demonstrate that HP presented the highest LS (24.24), and PWDs the lowest LS (21.05). PwNCDs are significantly more satisfied with their life than PwDs $(p<0.01)$, and if PwNCDs could live their life over, they would change almost nothing $(p<0.05)$. The mean score of assessed LS statements pointed to a higher LS of PwNCDs, as they declared higher LS in all five statements, and the mean total score also showedg significantly higher LS in PwNCDs compared to PwDs (22.27 vs 21.05; $p<0.01)$. Conclusions. Social relationships through appropriate physical activities and an active social life are extremely important for people with NCDs and disabilities, as they contribute to reducing their levels of social exclusion and isolation, which can lead to episodes of depression, stress, loneliness and consequent deterioration of health conditions.

Key words: noncommunicable diseases, disabled persons, adult, personal satisfaction, Satisfaction with Life Scale.

Bendíková E, Nemček D, Kurková P, Lubkowska W, Mroczek B. Satisfaction with life scale analyses among healthy people, people with noncommunicable diseases and people with disabilities. Fam Med Prim Care Rev 2018; 20(3): 210-213, doi: https://doi.org/10.5114/ fmpcr.2018.76917.

\section{Background}

Many people with noncommunicable diseases and disabilities have poor general health, limited community participation and a low quality of life. The emerging pandemic of noncommunicable diseases (NCDs) is creating major health challenges globally. NCDs are currently the leading cause of mortality, causing $68 \%$ of all deaths globally. Cardiovascular diseases, cancer, chronic respiratory and diabetes mellitus have been identified by the World Health Organization as the four major NCDs occurring worldwide [1].

There are more than 1000 million people with a disability globally, i.e. about $15 \%$ of the world's population or one in seven people. Of this number, between 110 million and 190 million adults experience significant difficulties in functioning [2].

Life satisfaction (LS) is a generic term commonly referred to as a person's subjective contentment with life and may refer to one's life evaluation, social skills and engagement in life activi- ties [3]. LS is often defined as a cognitive evaluation of one's current life situation compared to one's own unique set of criteria and is dependent on a person's adaptation process. In other words, LS reflects the degree to which individuals perceive that their own aspirations and achievements in life are met [4].

As LS is used as an overall goal in the management and rehabilitation of lifelong disabilities, it is important to determine the aspects of LS and factors that may influence it. One commonly used LS rating scale is the Satisfaction with Life Scale (SWLS). The SWLS offers a global measure of satisfaction with life and provides an overall summation of a person's life situation [4]. Some investigations have already been done to measure LS among people with NCDs and people with disabilities. Many of these studies indicated a lower LS in people with NCDs and people with disabilities compared to a healthy population.

Mudgal and Tiwari [5] measured the LS between participants diagnosed with HIV/AIDS and normal healthy persons with no reported chronic physical and/or mental health problems. They found a significantly lower level of LS compared to healthy par- 
ticipants. The reasons for low LS in people with NCDs are many. People with NCDs may become more sensitive, making them more easily offended than those of normal health [6]. Morrison and Bennett [7] reported that the inability of patients with NCDs in expressing their complaints to others can make them feel upset and non-understandable. This condition can certainly cause discomfort and result in interpersonal conflicts. Psychologically, this can also lead the patients to feel depressed, anxious and hopeless in facing their diseases or their disabilities.

The results of Chen and Crewe [8] indicated that the psychological variables of hope and acceptance of a disability, as well as spiritual well-being, were the best predictors of LS in a group of 218 individuals with progressive disabilities, as well as that demographic and background variables were less powerful predictors. A few longitudinal studies that have examined the relationship between disability and LS [e.g. 9, 10]. The main aim of all these analyses was to study whether people can adapt to a disability over time after its onset in terms of LS. According to the set point model, individuals return to a baseline LS after painful (such as divorce, widowhood, unemployment, disability, etc.) or cheerful (e.g. marriage, the birth of a child, lottery winnings, etc.) life events.

Considering previous research findings, the aim of our research was to (1) analyze the LS status using SWLS among healthy people, people with noncommunicable diseases and people with disabilities, and (2) to compare SWLS scores (five SWLS statements and SWLS total scores) within three evaluated groups.

The following problems and research hypotheses were formulated:

1. What is the life satisfaction (LS) of people with noncommunicable diseases and people with disabilities in comparison to healthy people?

2. Do people with noncommunicable diseases have higher life satisfaction than people with disabilities?

H1: Life satisfaction (LS) is lower in people with noncommunicable diseases and people with disabilities in comparison to healthy individuals.

H2: People with disabilities have lower life satisfaction (LS) compared to people with noncommunicable diseases.

\section{Material and methods}

\section{Participants and procedure}

Three main population groups $(n=1144)$ were recruited for the study: healthy people (HP; $n=313$ ), people with noncom- municable diseases (PwNCDs; $n=351$ ) and people with disabilities (PwDs; $n=480$ ). Intergroup variations were compared. The variables that differentiated the groups in the study were: noncommunicable disease, disability and health.

There were four main types of noncommunicable diseases in the research: cardiovascular diseases (e.g. heart attacks and stroke), cancer, chronic respiratory diseases (e.g. chronic obstructive pulmonary diseases and asthma) and diabetes mellitus.

Participants with NCDs and with disabilities were contacted through representatives of national organizations and schools all around Slovakia unifying people with different NCDs and with special needs. Some questionnaires were sent electronically by representatives of the organizations, and some were passed out at different meetings (e.g. general assembly, etc.) organized by national organizations. All data was collected over a two years period (2015-2016).

The study protocol was approved by the Ethics Committee of the Faculty of Physical Education and Sports, Comenius University in Bratislava, Slovakia.

\section{The Satisfaction with Life Scale (SWLS)}

The SWLS offers a global measure of satisfaction with life as an overall summation of a person's LS [4]. The SWLS consists of five items (statements) all tapping into global LS. In this study, a Slovak version of the SWLS was used [11].

\section{Data analyses}

Statistical analysis was undertaken using IBM SPSS version 23.0. Qualitative variables are presented as proportion and percentage. Quantitative variables are presented as a mean of standard deviation and range. Pearson's chi-square test was used to determine the differences between SWLS scores of healthy people, people with NCDs and people with disabilities. In the current study, only one measurement was made, and three main groups formed the study.

The level of statistical significance was set at $p<0.05$.

\section{Results}

\section{Participants}

In the research, $27.4 \%$ of HP, $30.7 \%$ PwNCDs and $41.9 \%$ PwDs participated. The group of HP presented a higher num-

\begin{tabular}{|c|c|c|c|c|}
\hline & & HP & PwNCDs $n(\%)$ & PwDs \\
\hline \multicolumn{2}{|c|}{ Baseline characteristics of participants } & $313(27.4)$ & $351(30.7)$ & 480 (41.9) \\
\hline \multirow[t]{2}{*}{ Gender } & Males & $187(59.7)$ & $166(47.3)$ & $240(50.0)$ \\
\hline & Females & $126(40.3)$ & $185(52.7)$ & $240(50.0)$ \\
\hline \multirow[t]{2}{*}{ Age } & Range $15-29$ years & $261(83.4)$ & $177(50.4)$ & $203(42.3)$ \\
\hline & Range $30+$ years & $52(16.6)$ & $174(49.6)$ & $277(57.7)$ \\
\hline \multirow[t]{3}{*}{ Education level } & Primary & $22(7.0)$ & $72(20.5)$ & $135(28.1)$ \\
\hline & High school & 225 (71.9) & $192(54.7)$ & $275(57.3)$ \\
\hline & University & $66(21.1)$ & $87(24.8)$ & $70(14.6)$ \\
\hline \multirow[t]{4}{*}{ Marital status } & Single & $274(87.5)$ & $190(54.1)$ & $256(53.3)$ \\
\hline & Married & $29(9.3)$ & $104(29.6)$ & $155(32.3)$ \\
\hline & Divorced & $7(2.2)$ & $20(5.8)$ & $40(8.3)$ \\
\hline & Widow & $3(1.0)$ & $37(10.5)$ & $29(6.1)$ \\
\hline \multirow[t]{4}{*}{ Employment status } & Employed & $38(12.1)$ & $101(28.8)$ & $174(36.3)$ \\
\hline & Unemployed & $9(2.9)$ & $11(3.1)$ & $52(10.8)$ \\
\hline & Student & $251(80.2)$ & $163(46.4)$ & $140(29.2)$ \\
\hline & Pensioner & $15(4.8)$ & $76(21.7)$ & 114 (23.8) \\
\hline
\end{tabular}




\begin{tabular}{|c|c|c|c|c|c|c|c|c|c|}
\hline Statement & HP & PwNCDs & PwDs & \multicolumn{2}{|c|}{ HP vs PwNCDs } & \multicolumn{2}{|c|}{ HP vs PwDs } & \multicolumn{2}{|c|}{ PwNCDs vs PwDs } \\
\hline No & \multicolumn{3}{|l|}{ mean } & $x^{2}$ & $p$ & $x^{2}$ & $p$ & $x^{2}$ & $p$ \\
\hline 1. & 4.933 & 4.362 & 4.148 & 38.89 & $0.00 * *$ & 68.21 & $0.00 * *$ & 13.05 & $0.04 *$ \\
\hline 2. & 5.380 & 4.840 & 4.454 & 43.55 & $0.00 * *$ & 92.54 & $0.00 * *$ & 30.68 & $0.00 * *$ \\
\hline 3. & 5.070 & 4.613 & 4.385 & 25.26 & $0.00 * *$ & 57.95 & $0.00 * *$ & 21.07 & $0.00 * *$ \\
\hline 4. & 4.866 & 4.744 & 4.458 & 11.22 & 0.08 & 18.72 & $0.00 * *$ & 25.08 & $0.00 * *$ \\
\hline 5. & 3.994 & 3.715 & 3.600 & 12.01 & 0.06 & 16.69 & $0.01^{*}$ & 12.73 & $0.04^{*}$ \\
\hline Total score & 24.24 & 22.27 & 21.05 & 24.80 & $0.00 * *$ & 64.96 & $0.00 * *$ & 20.64 & $0.00 * *$ \\
\hline
\end{tabular}

(1) The possible statement score range is $1-7$, and the possible total score range is 5-35; higher scores indicate better LS; (2)*level of statistical significance $p<0.05$; ${ }^{* *}$ level of statistical significance $p<0.01$.

ber of males (59.7\%), mostly represented in the range of 15-29 years of age $(83.4 \%)$. The HP population of our sample was mostly single $(87.5 \%)$, still studying $(80.2 \%)$ and had achieved a high school education level (71.9\%). On the other hand, the group of PwNCDs was represented mostly by females $(52.7 \%)$. Half of them were single (54.1\%), up to 30 years of age $(50.4 \%)$ and achieved a high school education level (54.7\%). Nearly half the number of PwNCDs were still studying (46.4\%), $28.8 \%$ had a full-time job, and $\mathbf{2 1 . 7 \%}$ were elderly pensioners or people in disability retirement. The group of PwDs comprised $50 \%$ males and $50 \%$ females. This group included more people over 30 years of age $(57.7 \%)$ than single people (53.3\%) at a high school education level (57.3\%). 36.3\% of PwDs were regular employees, $29.2 \%$ were still studying, and $23.8 \%$ were elderly pensioners or people in disability retirement (Table 1 ).

The group of PwNCDs included individuals with problems of internal systems and musculoskeletal disorders. The sample of PwNCDs comprised $26.9 \%$ with musculoskeletal impairments, $19 \%$ with cardiovascular diseases, $18.7 \%$ with metabolic diseases, and $15.4 \%$ covered people with other impairments, such as hormonal system impairments, cancer, problems with bowel movements and gynecologic impairments.

The group of PwDs comprised 59.7\% people with physical disabilities, $4.9 \%$ blind individuals and people with partial sight, and $35.4 \%$ people who are deaf or hard of hearing.

\section{SWLS}

The results of the study demonstrate significant differences between HP and PwNCDs in three evaluated LS statements and in the overall LS score (Table 2). In most ways, the life of HP is significantly closer to their ideal compared to PwNCDs $(p<$ 0.01 ). The conditions of their life are significantly more excellent than the life conditions of PwNCDs $(p<0.01)$. HP are significantly more satisfied with their life than PwNCDs $(p<0.01)$. The mean score of assessed LS statements pointed to a higher LS of $\mathrm{HP}$, as they declare higher LS in all five statements, as well as in the mean of total LS scores ( 24.24 vs $22.27 ; p<0.01$ ).

The results of the present study further demonstrate significant differences in LS between HP and PwDs in all evaluated LS statements as well as in the total LS score (Table 2). In most ways, the life of HP is significantly closer to their ideal compared to PwDs $(p<0.01)$. The conditions of their life are significantly more excellent than the life conditions of PwDs $(p<0.01)$. HP are significantly more satisfied with their life than PwDs $(p<$ 0.01 ). HP more frequently received the significantly important things they wanted in life than PWDs $(p<0.01)$, and if HP could live their life over, they would change almost nothing $(p<0.05)$. The mean score of assessed LS statements pointed to a higher LS of HP, as they declare higher LS in all five statements, and the mean of total score also showed significantly higher LS in HP compared to PwD (24.24 vs $21.05 ; p<0.01)$.

The results of the current study present significant differences in LS between PwNCDs and PwDs in all evaluated LS statements and in the overall LS score (Table 2).
The overall SWLS score of the evaluated groups demonstrate that HP presented the highest LS (24.24 of the point score), and PwDs the lowest LS (21.05 of the point score). HP, with a total SWLS score of 24.24 points, is the closest to a high score (range 25-29 points) from all assessed groups. On the other hand, PwDs, with a total SWLS score of 21.05 points, are closer to a score of 20 points, which represents the neutral point on the scale. This observed data generally showed that HP are the most satisfied with their life and PWDs are the most dissatisfied with their life when comparing all the assessed groups of the present study.

\section{Discussion}

In several studies, satisfaction with life has been associated with the health outcomes of people, in which LS plays an important role. People with chronic diseases and with disabilities are less likely to have access to health, rehabilitation, social support, income programs, education, leisure and employment, which increase the level of their well-being, and Piko [12] has found that younger individuals' psychosocial health should play an important role in the LS, particularly referring to psychosomatic symptoms, depressive disorders and health behaviors, such as food and tobacco consumption, which are factors that may impair the quality of life and health of the young adult population. The study by Clench-Aas et al. [13] explored the dimensionality and measurement invariance of SWLS across gender and age in a large $(n=4.984)$ Norwegian representative subsample of persons aged 15-79, including both male and female participants. Comparing the data of the current study, all evaluated groups of Slovak people achieved a much lower LS than the Norwegian groups of the population.

With increasing age, there is a higher appearance of chronic diseases, and later in life, many chronic diseases cause permanent disabilities. There is very strong evidence that participants with NCDs and disabilities participating in leisure time activities obtain and increase in physical and emotional health [14, 15]. Taking part in certain leisure activities can lead to different effects on the levels of LS according to the type of disability and disease. One very important leisure time activity that positively affects the level of $L S$ is physical activity and sport.

The results of the study by Bendíková and Nemček [16] demonstrate no significant differences in LS between HP participating in sport leisure activities and HP with a sedentary behavior. On the other hand, the same study revealed significantly higher LS in actively PWNCDs compared to inactive people with NCDs. Tasiemski et al. [17] investigated LS domains in patients with spinal cord injury and whether or not participation in sports and physical recreation was associated with LS. The authors reported a higher level of LS in general in patients with spinal cord injury who were involved in sports and physical recreation. The study by Yazicioglu et al. [18] showed that people with physical disabilities who participated in adapted sports had significantly higher quality of life and LS scores compared to people with 
physical disabilities not involved in any adapted sports. Another study by Kye and Park [19] also revealed that greater levels of happiness are associated with implementation of exercise.

\section{Conclusion}

Based on the aim of the current study, we found significantly higher LS in HP compared to PwNCDs and PwDs. Furthermore, we found significantly higher LS in PwNCDs compared to PwDs. According to the results and discussion of the present study, we need to emphasize the importance of having social relationships through appropriate physical activities and an active social life with, for example, friends, relatives, neighbors, teammates, at church, in civic associations, etc., which are extremely important for people with NCDs and disabilities, as they contribute to combating and reducing their levels of social exclusion and isolation, which can lead to episodes of depression, stress, loneliness and consequent deterioration of health conditions. General practitioners should, in particular, offer health counseling for people with disabilities and qualify them for special forms of residential and specialist care. In relation to people with noncommunicable diseases, general practitioners should recommend - in accordance with a general strategy to combat chronic noncommunicable diseases - physical activity and improved nutrition, which has a significant and often rapidly visible impact on public health.

Source of funding: This paper was supported by the grant project VEGA No. 1/0726/17.

Conflict of interest: The authors declare no conflict of interests.

\section{References}

1. World Health Organisation. Global Status Report on Noncommunicable Diseases. Geneva: WHO; 2014.

2. World Health Organisation. World Report on Disability. Geneva: WHO; 2011.

3. Kupcewicz E, Wróblewska T, Kędzia A, et al. Evaluation of life satisfaction and functional fitness of people over 60 years of age living in a nursing home and home environment. Fam Med Prim Care Rev 2016; 18(4): 437-442, doi: 10.5114/fmpcr.2016.63698.

4. Pavot W, Diener E. Review of the Satisfaction With Life Scale. Psychol Assessment 1993; 5(2): 164-172.

5. Mudgal S, Tiwari GK. Self-forgiveness and Life satisfaction in people living with HIV/AIDS. IJIP 2015; 3(1): 102-108.

6. Godsoe MR. Acceptance of chronic pain, attachment style, affectivity and treatment use. New Hampshire: Antioch University New England; 2008.

7. Morrison V, Bennett P. An Introduction to health psychology. 2rd ed. Madrid: Pearson Education Limited; 2009.

8. Chen RK, Crewe NM. Life satisfaction among people with progressive dicabilities. J Rehabil 2009; 75(2): 50-58.

9. Lucas R. Long-term disability is associated with lasting changes in subjective well-being: evidence from two national representative longitudinal studies. J Pers Soc Psychol 2007; 92(4): 717-780, doi: 10.1037/0022-3514.92.4.717.

10. Pagan R. Longitudinal analysis of the domains of satisfaction before and after disability: evidence from the German Socio-Economic Panel. Soc Indic Res 2012; 108(3): 365-385, doi: 10.1007/s11205-011-9889-3.

11. Nemček D. Stav kognitivnej zložky subjektivnej životnej pohody športujúcej a nešportujúcej populácie. Status of cognitive element of subjective well-being of active and inactive population. In: Žiak, pohyb, edukácia. Vedecký zborník [elektronický zdroj]. Bratislava: Univerzita Komenského; 2017: 198-207 (in Slovak).

12. Piko BF. Satisfaction with life, psychosocial health and materialism among Hungarian youth. J Health Psychol 2006; 11(6): 827-831, doi: $10.1177 / 1359105306069072$

13. Clench-Aas J, Nes R, Dalgard OS, et al. Dimensionality and measurement invariance in the Satisfaction with Life Scale in Norway. Qual Life Res 2011; 20: 1307-1317, doi: 10.1007/s11136-011-9859-x.

14. Devine M, Lashua B. Constructing social acceptance in inclusive leisure contexts: the role of individuals with disabilities. Ther Recreation J 2002; 36: 65-83.

15. Wilhite B, Shank J. In praise of sport: promoting sport participation as a mechanism of health among persons with a disability. Disabil Health J 2009; 2: 116-127, doi: 10.1016/j.dhjo.2009.01.002.

16. Bendíková $E$, Nemček D. Life satisfaction in healthy people and people with noncommunicable diseases: differences between active and inactive individuals. Sport Sci 2016: 9(2): 19-23.

17. Tasiemski T, Kennedy P, Gardner B, et al. The association of sports and physical recreation with life satisfaction in a community sample of people with spinal cord injuries. NeuroRehab 2005: 20(4): 253-265.

18. Yazicioglu K, Yavuz F, Goktepe AS, et al. Influence of adapted sports on quality of life and life satisfaction in sport participants and nonsport participants with physical disabilities. Disabil Health J 2012; 5: 249-253, doi: 10.1016/j.dhjo.2012.05.003.

19. Kye SY, Park K. Health-related determinants of happiness in Korean adults. Int J Public Health 2014; 59(5): 731-738, doi: 10.1007/ s00038-014-0588-0.

Tables: 2

Figures: 0

References: 19

Received: 15.05.2018

Reviewed: 16.05.2018

Accepted: 12.06 .2018

Address for correspondence:

Doc. Paed Dr. Elena Bendíková, PhD

Matej Bel University, Faculty of Arts

Department of Physical Education and Sports

97401 Banská Bystrica, Tajovského 40

Slovakia

Tel.: 00421484467556

E-mail: elena.bendikova@umb.sk 